\title{
Violence in Intimate Relationships: A Comparison between Married and Dating Couples
}

\author{
Carla Machado, ${ }^{1}$ Carla Martins, ${ }^{1}$ and Sónia Caridade ${ }^{2}$ \\ ${ }^{1}$ School of Psychology, University of Minho, Campus de Gualtar, 4710-057 Braga, Portugal \\ ${ }^{2}$ Faculty of Human and Social Sciences, University of Fernando Pessoa, Praça 9 de Abril, 349, 4249-004 Porto, Portugal \\ Correspondence should be addressed to Sónia Caridade; soniac@ufp.edu.pt
}

Received 17 April 2014; Revised 13 July 2014; Accepted 29 July 2014; Published 28 August 2014

Academic Editor: Julianne C. Flanagan

Copyright (c) 2014 Carla Machado et al. This is an open access article distributed under the Creative Commons Attribution License, which permits unrestricted use, distribution, and reproduction in any medium, provided the original work is properly cited.

\begin{abstract}
This study examines the attitudes about intimate violence and compares the prevalence of abuse reported by married and dating participants, by type of abuse and sex of respondent. A sample of 3,716 participants, aged 15 to 67 years, filled in one attitudinal questionnaire and a self-report instrument on abuse perpetration and victimization. Attitudinal data revealed a general disapproval of violence use, with greater violence support among males and married participants. When comparing violence in both relational contexts, we found that, in terms of perpetration, more dating partners reported physical abuse and severe forms of physical abuse than married partners. Suggestions for future research are discussed.
\end{abstract}

\section{Introduction}

Marital violence has been a widely studied topic since the seventies, whereas violence between dating partners has become the object of growing attention since Makepeace pioneer study in 1981 [1]. This study revealed that one in every five college students was affected by this problem, whereas $61 \%$ of participants revealed that they knew young people who had gone through an abusive dating experience. Since then, research on dating violence has increased steadily and considerably, assuming a prominent position in the relevant international scientific literature. Yet, studies that compare violence between dating and married couples are sparse in international research and inexistent in the Portuguese context. In the following literature review, we begin by showing how research in the area of marital and dating violence has increased; we then present and discuss the results of the few available studies comparing levels of violence across these two distinct relational contexts-marriage and dating; finally, we concentrate on investigations that analyze the relationships between attitudes and behaviors.

\section{Prevalence of Marital and Dating Violence}

Empirical findings show quite high levels of violence within both types of relationships. Regarding violence in married couples, the World Report on Violence and Health [2], based on information collected in 38 countries, places rates of lifetime prevalence at between $10 \%$ and $76 \%$. Similarly, a recent literature review in the European context reported high rates of victimization over lifetimes, varying from $16 \%$ to $39 \%$ [3]. As for the United States of America, researchers [4] found rates of lifetime prevalence ranging from $17.4 \%$ to $25.5 \%$. With respect to dating violence, research has also produced a wide variation of results, suggesting prevalence rates of offenders or victims ranging from $12.1 \%$ [5] to $72.4 \%$ [6]. An intercultural study in 31 universities from 16 countries showed that the rate of physical assault of dating partners in the previous 12 months ranged from $17 \%$ to $45 \%$ [7]. This great disparity and variability in the indicators of the prevalence of violence has been mainly attributed to different methodological options employed by studies (e.g., [8, 9]), including a lack of a clear definition of violence; the type of abuse measured and the great variety of instruments used in the measurement of violent behavior; sampling bias, including overrepresentation of the student population, particularly university students; the time period evaluated, such as during the previous year or lifelong; and the use of self-report measures of respondents. The results of these investigations, however, all highlight violence in intimate relationships as an important phenomenon deserving attention in itself. 
Data collected in Portugal, although sparse, confirms that dating violence is a significant social problem. For instance, in a large national sample composed of 4,667 participants, a significant number of students from various educational levels and age groups reported violent behaviors in their relationships (30.6\% global perpetration, $18.1 \%$ physical, and $22.4 \%$ emotional) [10]. The levels of violence found in the latter study [10] are somewhat higher than those reported in a study of a representative sample of married Portuguese couples, which used the same instruments (26\% global perpetration, $12 \%$ physical, and $24 \%$ emotional) [11]. The present study aims at expanding our understanding of violence in intimate relationships by comparing dating and married couples.

Research suggests that not only does violence tend to escalate in frequency and severity over time [12] but also that violence during dating is a strong precursor of marital violence, especially if the abusive love relationship persists over time [1]. Clinical studies also show that abusive marriages are generally preceded by violent dating relationships and are characterized by strategies to control and restrict women's autonomy [13]. The relevance of the study of violence in dating relationships is mainly concerned with three aspects: the magnitude and immediate impact on victims, their fragility and vulnerability, and the fact that dating violence can potentiate more serious aggression (such as physical and sexual violence) [14]. This evidence underscores the need to study the progression from dating violence to marital violence, through developing longitudinal studies that seek to compare evolutionary patterns of violence.

\section{Comparison of Marital and Dating Violence}

Some authors [15] have drawn attention to the undeniable relevance of examining theoretical and practical similarities and differences between these types of violence. So far, the few available studies have produced somewhat contradictory results. For instance, Frias and Angel [16] found that single women reported more victimization than married women, but Brown and Bulanda [15] obtained higher victimization levels in married partners, both men and women. Stets and Straus [17], however, found lower levels of violence in dating partners but Rouse et al. [18] found a similar pattern of results in terms of violence levels in married and dating partners. Some of these studies are quite dated [17], however, use small samples [18], specific samples (e.g., [16], who used a low income female sample), or make comparisons based on different measures [1].

Gender differences are one of the most debated topics when analyzing the literature on marital or dating aggression. Traditionally, males are more often regarded in the marital violence literature as the aggressors (e.g., $[10,19])$. For example, a recent study conducted in Portugal on gender violence based on a representative sample of 2000 participants showed that more men ( $77.8 \%$ compared to $27.3 \%$ of women) admitted the use of different forms of violence (physical, psychological, and sexual) [20]. However, in the case of dating violence, findings regarding gender effects are mixed and inconclusive. Whereas early studies reported higher victimization rates for females and higher perpetration rates for males (e.g., [1]), subsequent national (e.g., [21, 22]) and international research (e.g., $[7,23])$ reported similar rates of violence victimization for men and women, or even higher victimization rates among men (e.g., [24]). Other studies suggest that severe forms of violence are more likely to be perpetrated by females (e.g., [25]). For instance, Straus [7] found that rates of perpetration of minor and severe acts ranged from $17 \%$ to $48 \%$ for females and $16 \%$ to $38 \%$ for males. A recent longitudinal study using an ethnically diverse, communitybased sample of 13 to 19 year-olds of lower socioeconomic status found that females were significantly more likely to report dating violence aggression (38\%) than men (19\%) [26]. Taken together, these findings show that females are involved in abusive relationships as both victims and offenders. Furthermore, a recently published study showed that, not only are females likely to be perpetrators of violence, they are most likely to perpetrate violence in the context of mutually violent relationships, and their levels of perpetration are often higher than their levels of victimization [27].

Investigations comparing marital and dating violence in terms of gender differences also exhibit mixed and inconclusive findings [28]. Rouse et al. [18] found higher levels of moderate physical violence by males in both types of relationships. Contrastingly, Brown and Bulanda [15] found that married women are more likely than dating women to report violence perpetration and victimization, but dating men are less likely than married ones to report victimization. More recently, Straus' review [29] of more than 200 studies found gender symmetry in marital and dating relationships, both in perpetration and in risk factors and motives for physical violence. This study [29] concluded that most partner violence is mutual and that self-defense occurs only in a small proportion of partner violence cases by either men or women. This controversy over rates of male-female victimization or perpetration highlights how important it is to take gender into account when comparing married and dating relationships.

\section{Relationships between Attitudes and Violent Behaviors}

The literature on attitudes regarding intimate violence shows an association between behaviors and attitudes and/or beliefs that legitimize violence. It has been argued that attitudes are one of the most consistent predictors of abusive behavior (e.g., [30-32]); both victims and offenders often undervalue and/or minimise the occurrence of this type of violence dynamics [10, 33]. Furthermore, there is a tendency for adolescents to blame the victims for the occurrence of abusive incidents [34].

Even though there are empirical findings supporting a general disapproval of violence among youths [10] and adults [11], certain forms of violence are still accepted under certain circumstances $[7,35,36]$. Legitimizing beliefs seem to be higher among boys $[5,21]$, especially those professing more traditional attitudes toward gender roles [35], and between aggressors [11]. Others studies (e.g., [37]) suggest that acceptance of violence is more common after commitments have 
TABLE 1: Sample characteristics.

\begin{tabular}{lccc}
\hline & $\begin{array}{c}\text { Dating } \\
(n=1490)\end{array}$ & $\begin{array}{c}\text { Married } \\
(n=2226)\end{array}$ & Statistics \\
\hline Gender & & & \\
Male & $556(37.3 \%)$ & $1006(45.2 \%)$ & $\chi^{2}(1)=22.73^{* * *}$ \\
Female & $934(62.7 \%)$ & $1220(54.8 \%)$ & \\
Age & $18.9(2.33)$ & $37.1(7.01)$ & $t(3703)=-96.33^{* * *}$ \\
\hline${ }^{* * *} P<0.001$. & & &
\end{tabular}

been established. This gap between attitudes and behaviors found in many studies highlights the need to focus on this aspect.

\section{Current Study}

Our study with a large Portuguese sample is intended to fill the gap in the literature concerning studies that compare violence between dating and married couples in Portugal. Because the few available studies in this area have produced somewhat contradictory results, in the present study we used a broad Portuguese sample of dating and married couples, including students from various educational levels and age groups, assessed with the same validated measures of behaviors and attitudes. In this cross-sectional study, we believe that comparing levels of violence between these two different relational contexts is of relevance to identify the characteristics that are present in both marital and dating aggression; the findings may then help when developing appropriate preventive efforts to the different realities. In short, the aims of this study were (1) to examine and compare married and dating participants regarding their attitudes about intimate violence; (2) to analyze and contrast the reported prevalence of intimate violence, both perpetrated and received, in married and dating participants; and (3) to investigate gender differences in violent perpetration and victimization, by relationship type. Consistent with past research, it was hypothesized that participants involved in marital relationships tend to legitimize further violence and report higher indicators of severe violence, compared to participants involved in dating relationships. Likewise, it is expected that gender differences in terms of indicators of violence are higher in marital compared to dating relationships.

\section{Method}

6.1. Participants and Procedures. The final sample consisted of 3,716 Portuguese participants (2,154 females, 58\%), aged 15 to 67 years $(\mathrm{M}=29.8, \mathrm{SD}=10.53)$ (Table 1$)$. Most participants were married $(n=2226,59.9 \%)$. All participants lived in north Portugal.

This study was approved and financed by the Portuguese Foundation for Science and Technology. Nearly 10\% of the invited subjects, both married and dating, refused to participate (data on these subjects are not available). No economic compensation was provided, and all questionnaires were anonymous. Data collection was completed between 2004 and 2006.
The married sample included individuals from twoparent families with children under the age of 18 years. Potential participants who fitted this demographic profile and were identified through the local contacts of the researchers were contacted by various means, including professional associations, leisure clubs, church settings and sports and social organizations. Some were contacted directly by the research team; other contacts were mediated through local organizations. Each subject was then personally contacted by a researcher and invited to participate in the study. The questionnaires were individually completed by the participant or by the researcher if the individual claimed reading or comprehension difficulties.

The dating sample was obtained by convenience sampling through contacts with teachers in the different educational settings considered. The sample comprised secondary school students, professional school students (professional training schools for the same age group as secondary schools), and university students. All participants reported being in a current intimate relationship. Potential participants were invited to participate in the study and, if they agreed, they completed the questionnaires in a classroom with only the researcher present. Data were collected in two universities (44.5\%), five secondary schools (39.3\%), and seven professional schools (16.4\%) in north Portugal.

Informed consent was obtained from the participants as well as from school boards. Nearly $10 \%$ of the invited subjects refused to participate (data on these subjects are not available). No economic compensation was provided, and the participants were guaranteed full confidentiality. All questionnaires were anonymous. The questionnaires were completed by the participant in the class context.

6.2. Measures. Partner violence was investigated using an attitudinal scale, Scale of Beliefs about Marital Violence (ECVC, [38]), and a behavioral inventory, Marital Violence Inventory (IVC, [38]) validated in an earlier study [39]. Both were used in previous research projects on the topic of intimate violence in married or cohabiting adult couples [11] and dating partners [10].

The Scale of Beliefs about Marital Violence [38] comprises 25 items that assess the degree of approval of marital violence. The items correspond to beliefs that approve of support or minimize partner violence (e.g." "Insults are normal between partners"); close agreement with the items represents a higher global degree of support for partner violence. Participants indicated their degree of agreement with each statement on a 5-point Likert scale (giving a possible maximum score of 125). Each item presented a correlation with the total score ranging from 0.34 to 0.71 ; the global internal consistency of the total scale, measured by Cronbach's alpha, is 0.90 [39] (0.92 in the present sample). Factor analysis revealed four main factors $(F)$ that explain $48.1 \%$ of the variance, namely, $F 1$ : supporting violence through women's misconduct $(\alpha=0.85$; 0.80 in the present sample), explaining $30.5 \%$ of the common variance; $F 2$ : supporting violence through family privacy ( $\alpha=0.84 ; 0.88$ in the present sample), explicative of $6.9 \%$ of the variance; F3: supporting violence through external attributes $(\alpha=0.81 ; 0.82$ in the present sample), explaining 
TABLE 2: Violent practices according to gender and type of relationship.

\begin{tabular}{|c|c|c|c|c|}
\hline & & \multicolumn{2}{|c|}{ Gender } & \multirow[b]{2}{*}{$\chi^{2}(1)$} \\
\hline & & $\begin{array}{c}\text { Men } \\
N(\%)\end{array}$ & $\begin{array}{c}\text { Women } \\
N(\%)\end{array}$ & \\
\hline \multirow{4}{*}{ Aggression } & Any type of violent behavior & $461(30.7)$ & $600(29.5)$ & 0.64 \\
\hline & Physically violent behaviors & $209(14.0)$ & $290(14.4)$ & 0.12 \\
\hline & Severe forms of physical violence & $110(7.3)$ & $100(5.0)$ & $8.71^{* *}$ \\
\hline & Emotionally violent behaviors & $377(25.2)$ & $469(23.2)$ & 1.84 \\
\hline \multirow{6}{*}{ Victimization } & Any type of violent behavior & $360(28.4)$ & $551(30.1)$ & 1.14 \\
\hline & Physically violent behaviors & $148(11.9)$ & $242(13.5)$ & 1.70 \\
\hline & Severe forms of physical violence & $78(6.2)$ & $171(9.5)$ & $10.33^{* * *}$ \\
\hline & Emotionally violent behaviors & $300(23.8)$ & $468(25.8)$ & 1.49 \\
\hline & & \multicolumn{2}{|c|}{ Type of relationship } & \\
\hline & & $\begin{array}{l}\text { Dating } \\
N(\%)\end{array}$ & $\begin{array}{c}\text { Married } \\
N(\%)\end{array}$ & $\chi^{2}(1)$ \\
\hline \multirow{4}{*}{ Aggression } & Any type of violent behavior & $416(29.8)$ & $645(30.1)$ & 0.03 \\
\hline & Physically violent behaviors & $227(16.4)$ & $272(12.8)$ & $8.70^{* *}$ \\
\hline & Severe forms of physical violence & $111(8.0)$ & $99(4.7)$ & $16.57^{* * *}$ \\
\hline & Emotionally violent behaviors & $293(21.1)$ & $553(26.0)$ & $10.96^{* * *}$ \\
\hline \multirow{4}{*}{ Victimization } & Any type of violent behavior & $344(27.4)$ & $567(30.8)$ & $3.99^{*}$ \\
\hline & Physically violent behaviors & $154(12.4)$ & $236(13.1)$ & 0.28 \\
\hline & Severe forms of physical violence & $104(8.4)$ & $145(8.0)$ & 0.17 \\
\hline & Emotionally violent behaviors & $261(21.0)$ & $507(27.7)$ & $17.76^{* * *}$ \\
\hline
\end{tabular}

TABLE 3: Violent practices by gender in dating and married partners.

\begin{tabular}{|c|c|c|c|c|c|c|c|}
\hline & & \multicolumn{3}{|c|}{ Dating } & \multicolumn{3}{|c|}{ Married } \\
\hline & & $\begin{array}{c}\text { Men } \\
N(\%)\end{array}$ & $\begin{array}{l}\text { Women } \\
N(\%)\end{array}$ & $\chi^{2}(1)$ & $\begin{array}{c}\text { Men } \\
N(\%)\end{array}$ & $\begin{array}{c}\text { Women } \\
N(\%)\end{array}$ & $\chi^{2}(1)$ \\
\hline \multirow{4}{*}{ Aggression } & Any type of violent behavior & $150(28.6)$ & $266(30.5)$ & 0.57 & $311(31.8)$ & $334(28.7)$ & 2.53 \\
\hline & Physically violent behaviors & $76(14.6)$ & $151(17.4)$ & 1.90 & $133(13.6)$ & $139(12.1)$ & 1.14 \\
\hline & Severe forms of physical violence & $62(11.9)$ & $49(5.6)$ & $17.33^{* * *}$ & $48(4.9)$ & $51(4.4)$ & 0.27 \\
\hline & Emotionally violent behaviors & $110(21.1)$ & $183(21.1)$ & 0.00 & $267(27.4)$ & $286(24.8)$ & 1.86 \\
\hline \multirow{4}{*}{ Victimization } & Any type of abusive behavior & $30(30.4)$ & $214(25.9)$ & $2.95^{+}$ & $230(27.3)$ & $337(33.7)$ & $8.66^{* *}$ \\
\hline & Physically violent behaviors & $68(16.2)$ & $86(10.5)$ & $8.30^{* *}$ & $80(9.7)$ & $156(16.0)$ & $15.68^{* * *}$ \\
\hline & Severe forms of physical violence & $51(12.2)$ & $53(6.5)$ & $11.66^{* * *}$ & $27(3.3)$ & $118(12.0)$ & $46.67^{* * *}$ \\
\hline & Emotionally violent behaviors & $93(22.1)$ & $168(20.4)$ & 46 & $207(24.7)$ & $300(30.2)$ & $6.81^{* *}$ \\
\hline
\end{tabular}

${ }^{* * *} P<0.001 ;{ }^{* *} P<0.01 ;{ }^{+} P<0.10$.

$5.6 \%$ of the variance; and F4: minimizing small acts of violence ( $\alpha=0.72 ; 0.85$ in the present sample), explaining $5.1 \%$ of the variance.

The Marital Violence Inventory [38] asks questions about 21 different acts of violence (physical and emotional) towards partners during the past year. The response alternatives to each item are binary: "I never used this behavior with my present partner during the last year" or "I have used this behavior with my present partner during the last year." If an act of violence is admitted, individuals are asked how frequently that happened (e.g., "only once" or "more than once").
For statistical analyses, participants were considered aggressors if they reported having used at least one act classified as physically (e.g., "slapping face") or emotionally abusive (e.g., "threatening") during the preceding year (see Tables 2 and 3 for a more detailed view of the items included in the definition of partner abuse). The same procedure was adopted to establish whether or not an individual was a victim. Internal consistency, assessed through the Kuder-Richardson 20 coefficient, was found to be as follows: aggression: (i) physically violent behaviors, 0.58 ; (ii) severe forms of physical violence, 0.81 ; (iii) emotionally violent behaviors, 0.55 ; victimization: 


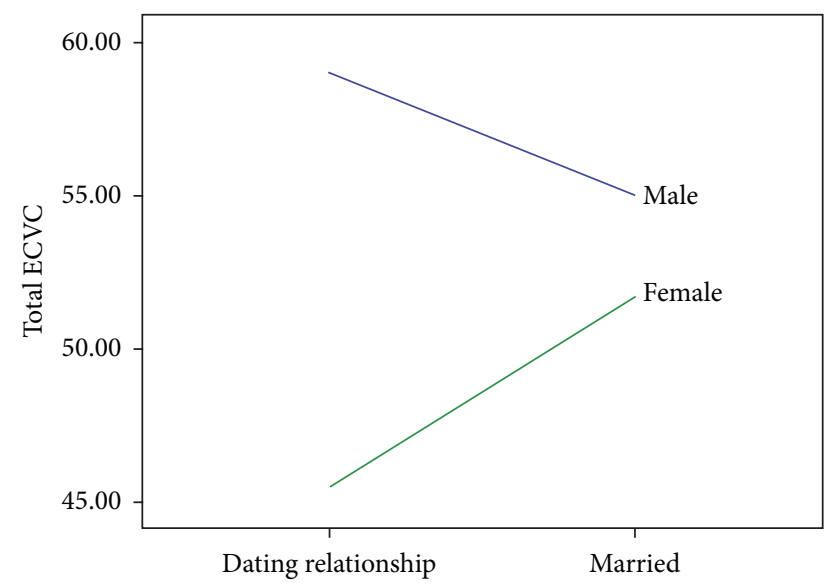

FIGURE 1: Violence legitimation.

(i) physically violent behaviors, 0.71 ; (ii) severe forms of physical violence, 0.88 ; (iii) emotionally violent behaviors, 0.70 .

\section{Results}

7.1. Attitudes to Partner Violence: Effect of Gender and Type of Relationship. The mean global score on the ECVC was 52.1 ( $\mathrm{SD}=15.25)$ with a range of 25 to 123 . This score is roughly equivalent to a mean response of 2 (disagree) to each of the items of the scale. Given that all the items indicated approval of or at least toleration the use of partner violence, this response tendency towards the lower end of the Likert scale indicates a global disagreement with the cultural myths that support partner abuse.

A two-way between-subject ANOVA revealed significant main effects of gender and type of relationship on violence supporting beliefs. Males displayed a higher degree of violence support than females, $F(1,3712)=284.52, P<$ 0.001 . Likewise, married participants exhibited higher mean levels of violence support than dating relationship partners, $F(1,3712)=4.97, P=0.026$. In addition, a significant gender $x$ type of relationship interaction emerged, $F(1,3712)=$ 104.70, $P<0.001$. Dating men were the strongest supporters of violence. In addition, as men were stronger supporters of violence when being in dating relationships, women approved violence more in the context of marriage than in the context of dating relationships (Figure 1).

7.2. Self-Reported Prevalence of the Perpetration and Victimization of Violence towards the Partner. Data obtained from 3,537 (95.2\%) participants were included in the analyses related to the self-report of perpetration of violence towards the partner. For victimization, data of 3,097 (83.3\%) participants were available. There were two reasons excluding participants in these analyses. Firstly, 179 participants $(4.8 \%)$ did not provide enough information on the IVC in order to be considered as an aggressor (adopting a conservative approach, it was decided not to classify as nonaggressors individuals who, despite not reporting any act of violence, did not reply to all items of the IVC). Secondly, 619 (16.7\%) did not provide enough information in order to be classified as victims of abuse by their partners; we opted for a conservative approach by deciding not to classify as nonvictims individuals who did not reply to all items of the IVC.

Regarding aggression, the most prevalent form of violence was emotional $(22.8 \%)$, and the least frequent was severe acts of physical violence (5.7\%). As for victimization, the results followed the same pattern, with the most prevalent form of violence being emotional (20.7\%) and the least frequent being severe acts of physical violence (6.7\%).

\subsection{Violent Practices: Associations with Gender and Type of Relationship}

Gender. Significant associations were found between gender and self-reported aggression involving severe forms of physical abuse, $\chi^{2}(1, N=3513)=8.71, P=0.003$, and self-reported experiences of severe forms of physical abuse, $\chi^{2}(1, N=3052)=10.33, P=0.001$. Whereas more males reported aggression involving severe physical abuse, more females were victims of this type of violence. No associations were found between gender and any other type of violent behavior (Table 2).

Type of Relationship. In terms of aggression, dating partners reported engaging in mild and severe physical violence more often than married partners, $\chi^{2}(1, N=3513)=8.70$, $P=0.003$, and $\chi^{2}(1, N=3513)=16.57, P<0.001$, respectively. Conversely, emotionally abusive behaviors were reported more frequently in married couples than in dating partners, $\chi^{2}(1, N=3518)=10.96, P=0.001$. Victimization is, according to the participants' reports, more prevalent in married couples in terms of any type of violent behavior, $\chi^{2}(1, N=3097)=3.99, P=0.046$, and specifically in terms of emotionally violent behaviors, $\chi^{2}(1, N=3073)=17.76$, $P<0.001$ (Table 2).

Gender versus Type of Relationship. In dating relationships, more men $(11.9 \%)$ than women $(5.6 \%)$ reported aggression involving severe forms of physical violence. In addition, men reported a higher prevalence of victimization of physical violence (16.2\% versus $10.5 \%$ in women) and severe physical violent behaviors (12.2\% versus $6.5 \%)$.

Within the married group, men and women reported a similar rate of violent behavior. However, for victimization, the prevalence is higher for married women, as opposed to married men, in terms of any type of violent behaviors $(33.7 \%$ versus $27.3 \%$ ), physical violence (16.0\% versus $9.7 \%)$, severe forms of physical violence (12.0\% versus 3.3\%), and emotional violence (30.2\% versus $24.7 \%$ ) (Table 3 ).

\section{Discussion}

As mentioned in Section 1, violence research has focused primarily on married couples and only recently has greater attention been paid to the prevalence of violence between dating partners. Studies that compare violence between dating and married couples are scarce in international research 
and inexistent in the Portuguese context. In comparing levels of violence across two different relational contextsmarriage and dating-this study brings an important and innovative contribution to the literature on partner violence. There is evidence (e.g., [1]) to show that violence in dating relationships is a precursor of marital violence and that the pattern of marital violence may be set in the dating period. Studies of this nature are necessary to identify the characteristics that are present in both marital and dating aggression so that effective interventions may be formulated that can interrupt the cycle of violence that starts in dating relationships and seems to escalate to more severe forms of violence in marriage.

8.1. Attitudes towards Partner Violence. In the overall sample, participants reported a general disapproval of the use of violence; however, both married and dating participants reported abuse that had occurred within the past year. Approximately one third of the participants reported perpetrating at least one act of violence on their partner during the preceding year, whereas about a quarter of the sample reported being a victim of at least one act of violence by their partner during the same period of time.

How to interpret this inconsistency between attitudes and behavior? From our view, this puzzling finding may reflect, on one hand, greater social awareness of intimate violence resulting from increasing efforts to raise awareness of the phenomenon (e.g., in the media and implementation of prevention programs in schools) [38]. On the other hand, this strong social discourse and judicial disapproval of violence is not yet associated with a visible impact on violent behavior. Some authors have attributed this contradiction between attitudes and behaviors to dissonance between three aspects: the way the participants were raised (violent socialization), their beliefs, and what is now said and commonly accepted. This discrepancy might be due to the legitimizing of violence in our society (e.g., "A slap hurts nobody"; "An unfaithful partner deserves to be mistreated"; "Slapping your partner when you are upset or angry is normal; is one without gravity") that coexists with other beliefs that disapprove of and penalize violence [40].

\subsection{Attitudes towards Partner Violence by Gender and Type of} Relationship. A detailed analysis of attitudinal data has also revealed that the disapproval of violence is not uniform across the sample, thus corroborating previous data $[10,11,40]$. Men are more tolerant towards violence, which might reflect some socialization practices of gender; traditionally, men have been brought up to be stronger, emotionally inexpressive, competitive, and dominant with their partners, and women were encouraged to be submissive and not express anger (cf. [41]). Likewise, married individuals showed a higher level of violence support. Changing status by marrying appears to be more relational and associated with the adoption of more traditional roles. More specifically, the constraints often associated with marriage (e.g., greater economic dependence, cohabitation, children, etc.) may lead partners to adopt traditional models of gender relations, leaving behind the parity that tends to characterize dating relationships [40].
8.3. Violent Practices. In terms of the prevalence of perpetration and victimization, the levels of violence found in our investigation are similar to those reported by other national $[11,21,22]$ and international authors (e.g., [7, 42]). However, we found higher levels of physical violence and severe physical violence in dating partners. Our data suggests, therefore, that violence is not decreasing amongst younger generations; dating may now even involve more severe forms of violence.

The high levels of violence reported in dating partners have been partly attributed to the specific dynamics of such a relationship (e.g., less reliance on partners, a potentially easier break up, and no children) (e.g., $[15,28]$ ), that can more easily promote feelings of greater insecurity, conflict, and interpersonal stress. Concomitantly, power and control have also been associated with violence in dating relationships [15]. A recent review of the literature documented an association between control/dominance (male or female) and the use of violence in relationships [43]. The author claims that in cases of domain/control relationships, there is an increased risk of the use of physical violence. By contrast, in marriage there is a trend towards greater tolerance towards controlling attempts by the partner, with men assuming the right to control women [15]. This may explain a decrease in the conflict and gives validity to Stets and Straus's words "... the marriage license may also be a control license" [17, p. 177]. The higher prevalence of emotional abuse reported in marital couples (26\%) compared to dating partners (21.1\%) may, in our view, sustain this argument.

8.4. Violent Practices by Gender and Type Relationships. In this investigation, aggression and victimization in married and dating couples were found to be associated with gender. Regarding the dating participants, some results contradict a previous study by Machado and colleagues [10] that used the same measures and therefore must be interpreted carefully. However, we believe that conflicting findings are mainly due to sample selection as, in this study, we only included participants from north Portugal (where the population shares more conservative and legitimating values of male violence); in the study by Straus [7] the participants came from different geographical areas of the country (diluting the differences).

Dating men (11.9\%) were somewhat more likely than woman $(5.6 \%)$ to report that their partner had used severe physical violence; this is in line with previous data (e.g., $[44,45])$ that attribute the responsibility of severe abuse to males. It has been argued that women perpetrate a less severe type of violence but suffer more severe violence (e.g., $[44,46])$. This finding has also been found in the present investigation with women identifying themselves as the main victims of severe physical abuse. For other forms of violence (global, emotional, and physical) in dating relationships, there was no association with gender, contrary to the findings of another study [10], in which more females than males reported violence (global, emotional, and physical) on their dating partners. Thus, we consider that gender differences in dating violence in Portugal are still a topic that needs further exploration and contextualization. 
With respect to married couples and the pattern of aggression, there was gender parity in the different forms of violence studied that may be partly explained by the characteristics of the sample (normative population). However, these results seem to partly contradict the usual view of domestic violence as an issue of violence against women, perpetrated by men. The results are also consistent with those of other studies that support the view that women can be as violent as men and may start the abuse cycle [17]. Nevertheless, without knowing the context of the acts and without access to data about the underlying motivations and sequence of events, it would be inappropriate to conclude that such data imply a minimization of the gender dimension of this problem. We agree with Casimiro [19] when she suggests that the problem of domestic violence should not only be regarded as a gender issue but also the explanatory framework in this area should be extended by hypothesizing, for instance, that marital dynamics inevitably change with time (e.g., marital styles adopted by the subjects may collide with each other and tension between the individual versus the sometimes high marital expectations, around the lives of them).

In terms of gender differences in dating relationships, more males than females reported being victims, both in terms of severe physical violence (12.2.\% versus $6.5 \%$, resp.) and physical violence $(16.2 \%$ versus $10.5 \%$, resp.). These results represent an unexpected finding, given that Machado et al. [10] did not find statistically significant gender differences for overall victimization or severe physical and emotional victimization. Moreover, these results seem dissonant with stereotypes about male dominance and autonomy that often appear to undermine help-seeking behaviors by men. Other studies (e.g., [44]) have shown that men suffer a particular type of moderate violence. However, other empirical findings (e.g., [42, 47]) give some support to our results, when considering that women may use a more severe type of violence. Nevertheless, most research also considers that female physical violence is used primarily in the context of selfdefense and mutually violent relationships [27]. Furthermore, women with a lower tolerance to violence associated with a higher awareness of their rights may generate more conflict that possibly culminates in episodes of physical violence. Finally, the finding that married women were the main victims of different forms of violence studied (physical, severe physical, and emotional) is consistent with other studies (e.g., $[18,40])$. These data have been interpreted in the light of socialization that makes women more vulnerable and more emotionally dependent on the relational dimensions of their lives [40].

\section{Conclusion}

Our findings suggest that dating violence is a problem in Portugal and that partner violence is not exclusive to married couples. These findings seem to contradict the common belief that violence among young people is declining and that severe physical violence only takes place within marriage. Future longitudinal studies comparing evolutionary patterns will allow for greater clarification of this aspect.
Our results, however, are not conclusive regarding gender. Although in both relational contexts there was more parity in terms of violence, this did not appear to extend to all forms of violence. In dating relationships, males reported perpetrating and being victims of severe physical violence, whereas married women were the most victimized regarding all forms of violence.

Overall, these results highlight the need to further explore and clarify the issue of gender in intimate relationships. Because our current research and other studies show high rates of mutual violence, it is imperative to understand the motives, contexts, and meanings of the reported episodes of violence. More specifically, future research will need to examine the motives for women's violent aggression, and how these acts impact on their experiences as victims, the context in which they practice violence as primary aggressors, or if they use violence only in self-defense.

The main strength of the present investigation is its large national sample, including students from various educational levels and age groups and the use of validated measures of behaviors and attitudes with respect to violence in intimate relationships.

This study has limitations that should be mentioned. Firstly, its convenience sample does not allow for generalization to the Portuguese population. Secondly, some scales of Marital Violence Inventory, concerning aggression (physically violent behaviors and emotionally violent behaviors), have lower than desirable internal consistency values. That might be due to the fact that this instrument resembles a checklist for the participants to answer whether or not they have perpetrated several types of violence; therefore, the participant might have performed an act(s) but not others. Thirdly, our study did not include the assessment of the most severe kinds of violence, such as sexual violence and terrorizing forms of intimate partner violence recognized by Johnson [48] that tend to be more commonly perpetrated by men and have the most negative consequences. Clinical or shelter samples can provide information about these forms of partner violence [48]. Fourthly, the study has focused solely on heterosexual relationships, meaning that more research is needed that focuses on same-sex partners, where violence is also a concern [49]. It is necessary to extend investigations to other relational contexts, such as cohabiting couples or former spouses (divorced or separated). For instance, Brown and Bulanda [15] suggest that cohabitation is more associated with violence than marriage, at least for women. In their study, cohabiting women were more likely than married women to behave violently toward their partners and to experience violence at the hands of their partners.

Intimate violence as a phenomenon across different relational contexts (dating, marriage, cohabiting) justifies the investment in research in order to develop and implement programs to prevent violence. Moreover, it is important that prevention efforts are structured long-term interventions. While awareness and information campaigns are important, in our view they are insufficient to fight this phenomenon. Our results support the development of prevention strategies aimed at dating violence, a relational reality more meaningful for teenagers than that of domestic violence. 


\section{Conflict of Interests}

The authors declare that there is no conflict of interests regarding the publication of this paper.

\section{Acknowledgment}

This study was conducted within the research project "Multiple victimisation of socially excluded women: the intersection of meanings and trajectories of change" (PTDC/PSIAPL/113885/2009), funded by the Portuguese Foundation for Science and Technology.

\section{References}

[1] J. M. Makepeace, "Courtship violence among college students," Family Relations, vol. 30, pp. 97-102, 1981.

[2] World Health Organization, World Report on Violence and Health, WHO, Geneva, Switzerland, 2003.

[3] C. Machado and A. R. Dias, "Cultura e violência familiar: uma revisão crítica da literatura," Revista Brasileira de Informação Bibliográfica em Ciências Sociais, vol. 64, pp. 43-47, 2008.

[4] K. Malley-Morrison and D. A. Hines, Family Violence in a Cultural Perspective, Sage, Thousand Oaks, Calif, USA, 2004.

[5] J. Henton, R. Cate, J. Koval, S. Lloyd, and S. Christopher, "Romance and violence in dating relationships," Journal of Family Issues, vol. 4, pp. 467-482, 1983.

[6] T. Aldrighi, "Prevalência e cronicidade da violência física no namoro entre jovens universitários do estado de São PauloBrasil," Psicologia: Teoria e Prática, vol. 6, pp. 105-120, 2004.

[7] M. A. Straus, "Prevalence of violence against dating partners by male and female university students worldwide," Violence Against Women, vol. 10, no. 7, pp. 790-811, 2004.

[8] S. M. Jackson, "Issues in the dating violence research: a review of the literature," Aggression and Violent Behavior, vol. 4, no. 2, pp. 233-247, 1999.

[9] S. F. Lewis and W. Fremouw, "Dating violence: a critical review of the literature," Clinical Psychology Review, vol. 21, no. 1, pp. 105-127, 2001.

[10] C. Machado, S. Caridade, and C. Martins, "Violence in juvenile dating relationships self-reported prevalence and attitudes in a portuguese sample," Journal of Family Violence, vol. 25, no. 1, pp. 43-52, 2009.

[11] C. Machado, M. M. Gonçalves, M. Matos, and A. R. Dias, "Child and partner abuse: self-reported prevalence and attitudes in the north of Portugal," Child Abuse \& Neglect, vol. 31, no. 6, pp. 657670, 2007.

[12] L. K. Hamberger and A. Holtzworth-Munroe, "Partner violence," in Cognitive-Behavioral Strategies in Crises Intervention, F. Dattilio and A. Freeman, Eds., pp. 302-322, Guilford Press, New York, NY, USA, 1994.

[13] M. Matos, Violência conjugal: Oprocesso de construção da identidade da mulher [Dissertação de candidatura ao grau de mestre em Psicologia, na especialidade de Psicologia da Justiça], Instituto de Educação e Psicologia, Universidade do Minho, Braga, Portugal, 2000.

[14] S. Caridade, Vivências Intimas Violentas. Uma Abordagem Científica, Almedina Coimbra, 2011.

[15] S. L. Brown and J. R. Bulanda, "Relationship violence in young adulthood: a comparison of daters, cohabitors, and marrieds," Social Science Research, vol. 37, no. 1, pp. 73-87, 2008.
[16] S. M. Frias and R. J. Angel, "The risk of partner violence among low-income hispanic subgroups," Journal of Marriage and Family, vol. 67, no. 3, pp. 552-564, 2005.

[17] J. E. Stets and M. A. Straus, “The marriage license as a hitting license: a comparison of assaults in dating, cohabiting, and married couples," Journal of Family Violence, vol. 4, no. 2, pp. 161-180, 1989.

[18] L. P. Rouse, R. Breen, and M. Howell, "Abuse in intimate relationships. A comparison of married and dating college students," Journal of Interpersonal Violence, vol. 3, pp. 414-429, 1988.

[19] C. Casimiro, "Violências na conjugalidade: a questão da simetria de género," Análise Social, vol. 43, pp. 579-601, 2010.

[20] Socinova/Cesnova/FCSH, "Memorando Síntese. Resultados do Inquérito Violência de Género," Documento apresentado à CIG, 2008.

[21] C. Machado, M. Matos, and A. I. Moreira, "Violência nas relações amorosas: Comportamentos e atitudes na população universitária," Psychologica, vol. 33, pp. 69-83, 2003.

[22] C. Paiva and B. Figueiredo, "Abuso no relacionamento íntimo: estudo de prevalência em jovens adultos portugueses," Psychologica, vol. 36, pp. 75-107, 2004.

[23] V. M. Follette and P. C. Alexander, "Dating violence: current and historical correlates," Behavioral Assessment, vol. 14, no. 1, pp. 39-52, 1992.

[24] J. J. Cercone, S. R. H. Beach, and I. Arias, "Gender symmetry in dating intimate partner violence: does similar behavior imply similar constructs?" Violence and Victims, vol. 20, no. 2, pp. 207218, 2005.

[25] V. A. Foshee, "Gender differences in adolescent dating abuse: prevalence, types and injuries," Health Education Research, vol. 11, no. 3, pp. 275-286, 1996.

[26] S. Jain, S. L. Buka, S. V. Subramanian, and B. E. Molnar, "Neighborhood predictors of dating violence victimization and perpetration in young adulthood: a multilevel study," The American Journal of Public Health, vol. 100, no. 9, pp. 1737-1744, 2010.

[27] C. Kaukinen, A. R. Gover, and J. L. Hartman, “College women's experiences of dating violence in casual and exclusive relationships," American Journal of Criminal Justice, vol. 37, no. 2, pp. 146-162, 2012.

[28] R. C. Shorey, T. L. Cornelius, and K. M. Bell, "A critical review of theoretical frameworks for dating violence: comparing the dating and marital fields," Aggression and Violent Behavior, vol. 13, no. 3, pp. 185-194, 2008.

[29] M. A. Straus, “Thirty years of denying the evidence on gender symmetry in partner violence: implications for prevention and treatment," Partner Abuse, vol. 1, pp. 332-361, 2010.

[30] S. Avery-Leaf, M. Cascardi, K. D. O'Leary, and A. Cano, "Efficacy of a dating violence prevention program on attitudes justifying aggression," Journal of Adolescent Health, vol. 21, no. 1, pp. 11-17, 1997.

[31] D. S. Riggs and K. D. O'Leary, "Aggression between heterosexual dating partners: an examination of a causal model of courtship aggression," Journal of Interpersonal Violence, vol. 11, no. 4, pp. 519-540, 1996.

[32] P. Tontodonato and B. K. Crew, "Dating violence, social learning theory, and gender: a multivariate analysis," Violence and Victims, vol. 7, no. 1, pp. 3-14, 1992.

[33] F. Ismail, H. Berman, and C. Ward-Griffin, "Dating violence and the health of young women: a feminist narrative study," Health Care for Women International, vol. 28, no. 5, pp. 453-477, 2007. 
[34] F. Lavoie, L. Robitaille, and M. Hébert, "Teen dating relationships and aggression: an exploratory study," Violence against Women, vol. 6, no. 1, pp. 6-36, 2000.

[35] E. L. Price, S. E. Byers, N. Belliveau et al., "The attitudes towards dating violence scales: development and initial validation," Journal of Family Violence, vol. 14, no. 4, pp. 351-375, 1999.

[36] H. A. Sears, E. S. Byers, J. J. Whelan, and M. Saint-Pierre, “"If it hurts you, then it is not a joke": adolescents "ideas about girls" and boys' use and experience of abusive behavior in dating relationships," Journal of Interpersonal Violence, vol. 21, no. 9, pp. 1191-1207, 2006.

[37] T. M. Bethke and D. M. Dejoy, "An experimental study of factors influencing the acceptability of dating violence," Journal of Interpersonal Violence, vol. 8, pp. 36-51, 1993.

[38] C. Machado, M. Matos, and M. Gonçalves, "Manual da Escala de Crenças sobre Violência Conjugal (E.C.V.C.) e do Inventário de Violência Conjugal (I.V.C.)," Psiquilíbrios Edições, Braga, Portugal, 2008.

[39] C. Machado, M. Matos, and M. Gonçalves, "Avaliação psicológica," in Instrumentos Validados Para a População Portuguesa, L. Almeida, M. Simões, C. Machado, and M. M. Gonçalves, Eds., pp. 127-140, Coords, Coimbra, Portugal, 2004.

[40] C. Machado, "Violência nas famílias portuguesas: um estudo representativo na região Norte," Psychologica, vol. 40, pp. 173194, 2005.

[41] D. A. Wolfe, C. Wekerle, and K. Scott, Alternatives to Violence. Empowering Youth to Develop Healthy Relationships, Sage, London, UK, 1997.

[42] L. Magdol, T. E. Moffitt, A. Caspi, D. L. Newman, J. Fagan, and P. A. Silva, "Gender differences in partner violence in a birth cohort of 21-year- olds: bridging the gap between clinical and epidemiological approaches," Journal of Consulting and Clinical Psychology, vol. 65, no. 1, pp. 68-78, 1997.

[43] M. A. Straus, "Dominance and symmetry in partner violence by male and female university students in 32 nations," Children and Youth Services Review, vol. 30, no. 3, pp. 252-275, 2008.

[44] X. B. Arriaga and V. A. Foshee, "Adolescent dating violence. Do adolescents follow in their friends', or their parents, footsteps?" Journal of Interpersonal Violence, vol. 19, no. 2, pp. 162-184, 2004.

[45] M. Schiff and A. Zeira, "Dating violence and sexual risk behaviors in a sample of at-risk Israeli youth," Child Abuse \& Neglect, vol. 29, no. 11, pp. 1249-1263, 2005.

[46] C. Molidor and R. M. Tolman, "Gender and contextual factors in adolescent dating violence," Violence against Women, vol. 4, no. 2, pp. 180-194, 1998.

[47] J. E. Stets and D. A. Henderson, "Contextual factors surrounding conflict resolution while dating: results from a national study," Family Relations, vol. 40, pp. 29-36, 1991.

[48] M. P. Johnson, "Patriarchal terrorism and common couple violence: two forms of violence against women," Journal of Marriage and Family, vol. 67, pp. 1126-1130, 1995.

[49] R. Antunes and C. Machado, "Dupla invisibilidade: a violência nas relações R., homossexuais," Psychologica, vol.39, pp. 167-187, 2005. 

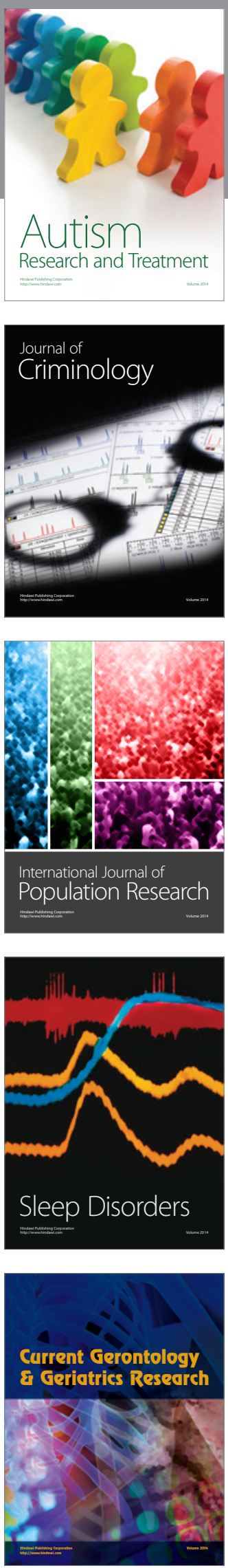
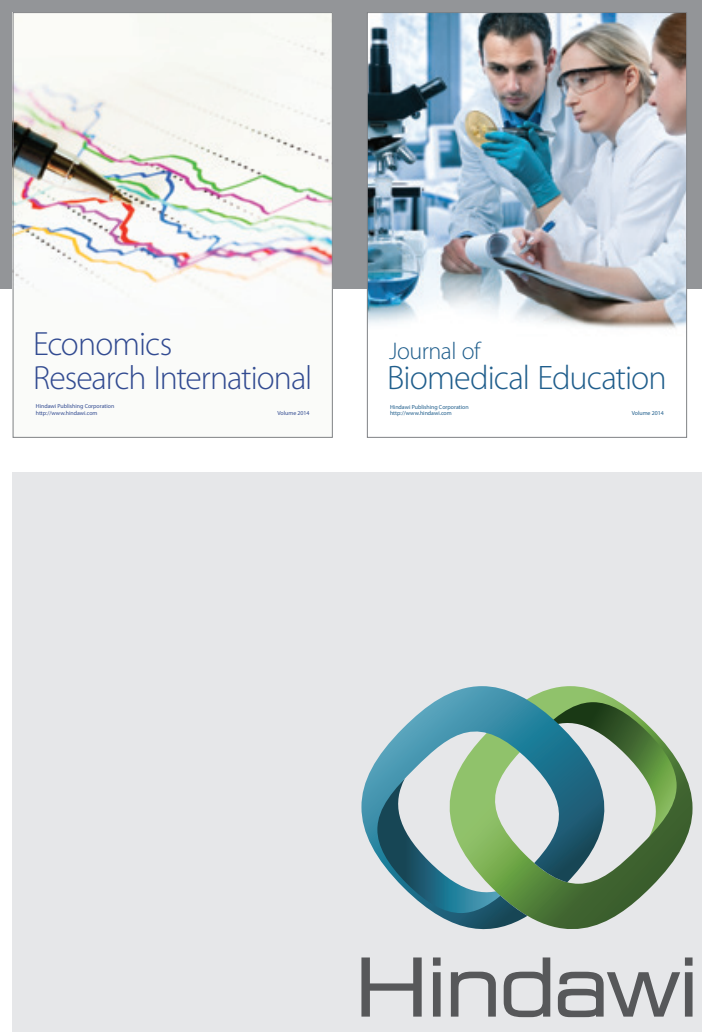

Submit your manuscripts at

http://www.hindawi.com
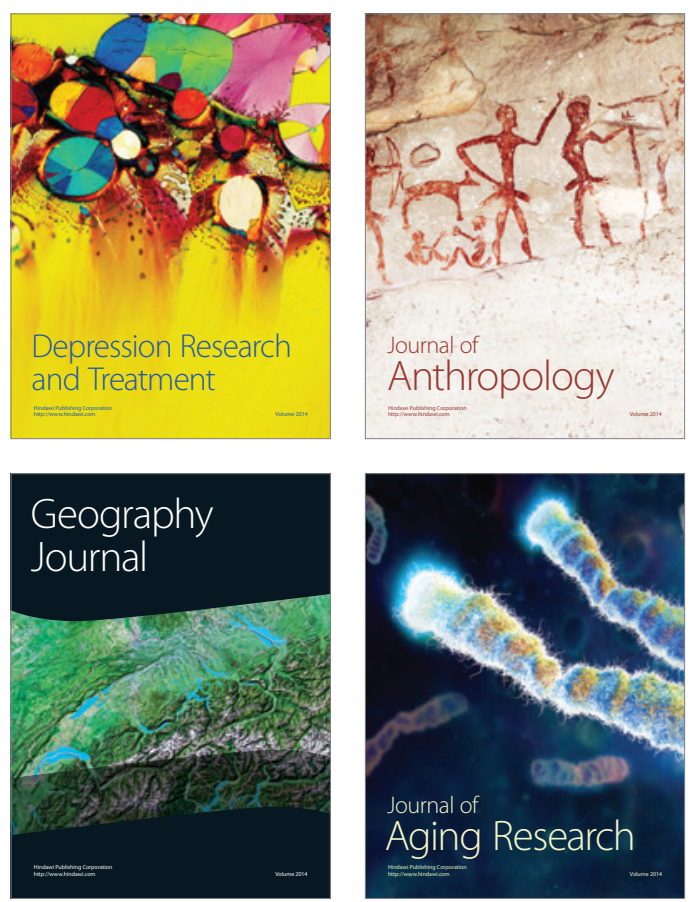
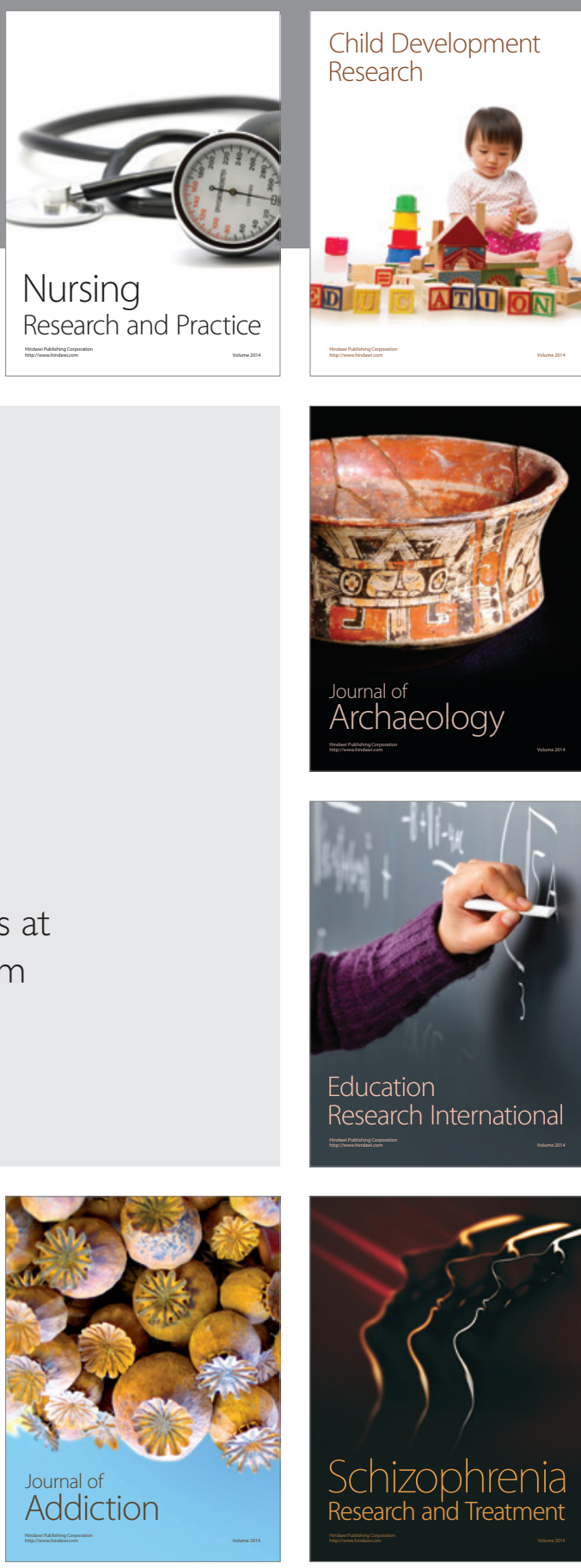

(D)
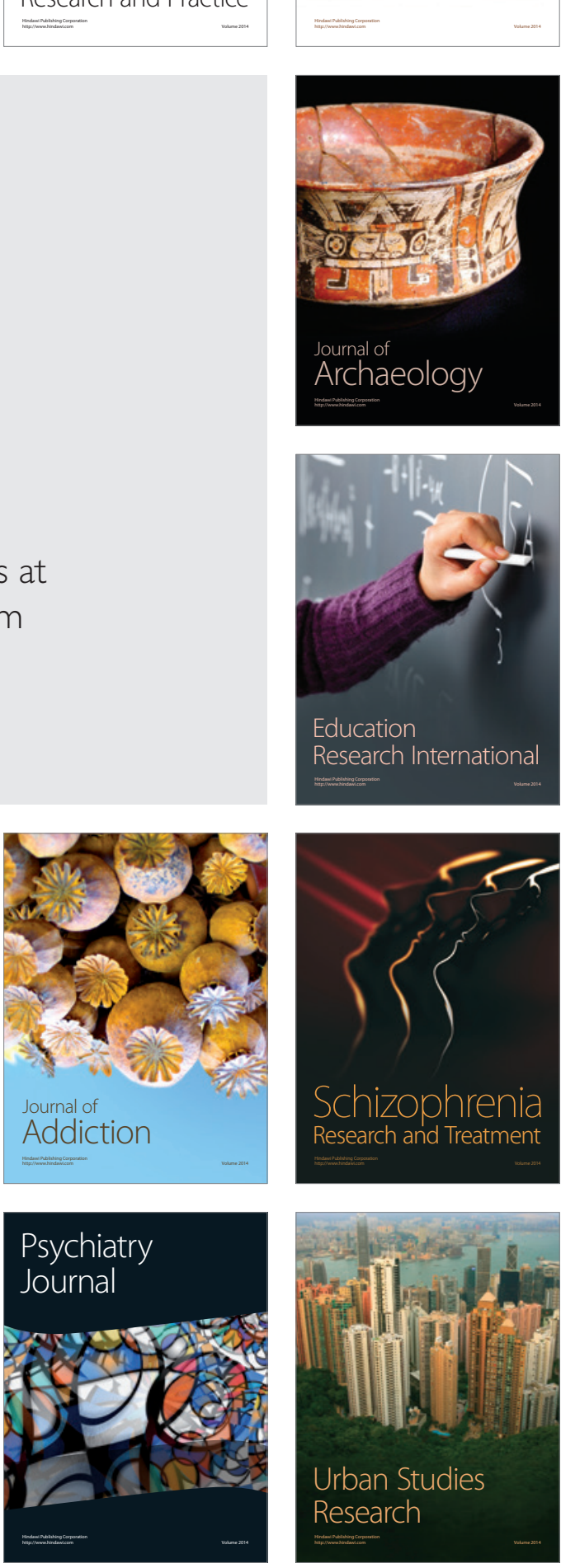